\title{
Intravenous Methylprednisolone Pulse Therapy for Graves' Ophthalmopathy
}

\author{
YuJi HIROMATSU, KiYOKo TANAKA, \\ Masayuki SATO, Toshitaka KUROKI, \\ KYOHEI NONAKA, KAZUYUKI KOJIMA*, \\ Hiroshi NISHIMURA*, Hiroshi NISHIDA** AND \\ Nobuko KAISE*** \\ Division of Endocrinology and Metabolism, The Department of \\ Medicine, The Departments of *Radiology, and **Ophthalmology, \\ Kurume University School of Medicine, Fukuoka 830, and \\ ***The Second Department of Internal Medicine, Tohoku \\ University School of Medicine, Sendai 980, Japan
}

\begin{abstract}
To investigate the efficacy of intravenous methylprednisolone pulse therapy on Graves' ophthalmopathy (GO), fifteen patients with severe $\mathrm{GO}$ were treated with large dose intravenous methylprednisolone (at a daily dosage of $1 \mathrm{~g}$ for 3 successive days). This treatment was repeated 3-5 times for 3-5 weeks. They were monitored before, 2 weeks after and 6 months after therapy by ophthalmological assessment, orbital magnetic resonance imaging (MRI), and by measuring serum antibodies to rat eye muscle (EMAB) in an enzyme linked immunosorbent assay and peripheral blood lymphocyte subsets by flow cytometry. Diplopia and periorbital edema markedly improved after treatment in 9 patients. Mean proptosis values and intraocular pressure measurements significantly decreased after pulse therapy. In 12 patients enlarged eye muscles significantly reduced in size after treatment, as determined by MRI. The overall ophthalmopathy index was improved from $4.8 \pm 2.4$ to $2.5 \pm 1.6$ at the end of pulse therapy $(P<0.01)$ and $2.4 \pm 1.5$ six months after therapy $(P<0.01)$. Serum EMAB were detected in 8 out of 10 patients tested and their level significantly decreased after pulse therapy (from $3.3 \pm 1.4$ to $2.5 \pm 1.2, P<0.01$ ). A significant increase in peripheral blood CD4 ${ }^{+} \mathrm{CD}_{45 \mathrm{RA}}{ }^{+}$ cells was observed after pulse therapy. Increased numbers of $\mathrm{CD} 11^{-} \mathrm{CD} 8^{+}$cells and decreased numbers of $\mathrm{CD} 11^{+} \mathrm{CD}^{++}$cells were found prior to treatment and were normalized after pulse therapy. Our study indicates that methylprednisolone pulse therapy can be considered as a choice for the treatment of GO. The improvement in eye muscle involvement in these patients may be due to the effects of infused methylprednisolone on both humoral and cellular immune functions.
\end{abstract}

Key words: Graves' ophthalmopathy, Pulse therapy, Eye muscle antibody, T cell subsets, MRI.

(Endocrine Journal 40: 63-72, 1993)

GRAVES' disease is an autoimmune disorder commonly associated with ophthalmopathy, characterized by periorbital edema, proptosis, ex-

Received: June 10, 1992

Accepted: November 20, 1992

Correspondence to: Dr. Yuji HIROMATSU, Division of Endocrinology and Metabolism, The Department of Medicine, Kurume University School of Medicine, 67 Asahi-machi, Kurume, Fukuoka 830, Japan traocular muscle dysfunction, keratitis and optic nerve compression. Although the pathogenesis of Graves' ophthalmopathy (GO) is not known, there is considerable evidence for autoimmune reactions directed to orbital antigens, in particular to eye muscle [1-3]. On the basis of the immunological mechanisms producing the inflammatory changes in the orbit, attempts have been made to control the immunological reactions of GO with immuno- 
suppressive drugs such as corticosteroids [4], cyclophosphamide [5] and cyclosporin A [6, 7] and with plasma exchange [8] for the treatment of GO or its prevention [9]. Recently, large doses of methylprednisolone have been given intravenously with some beneficial effects on GO [10-12] as well as on other autoimmune disorders such as lupus nephritis [13] without the appearance of severe adverse reactions.

In the present study we have assessed the efficacy of intravenous steroid therapy in GO, by quantitating the changes in various clinical parameters, namely proptosis, intraocular pressure (IOP), the thickness of the extraocular muscle, as measured by magnetic resonance imaging (MRI), the detectability of eye muscle antibodies (EMAB) by enzyme linked immunosorbent assay (ELISA) and the measurement of peripheral blood $\mathrm{T}$ and natural killer (NK) cell subsets by flow cytometry.

\section{Subjects and Methods}

Fifteen patients, 9 men and 6 women, with Graves' disease, aged 20-75 years (mean age 48 years) with clinically evident eye disease of from 3 months to 4 years' duration, were included in the study. Eleven patients had class IV, two patients had class $\mathrm{V}$ and two patients had class VI eye disease as defined by the American Thyroid Association Classification Committee [14]. Twelve patients had hyperthyroid Graves' disease, all of them euthyroid at the time when steroid treatment was begun, 7 having been treated with anti-thyroid drugs and 4 euthyroid on thyroxine replacement after thyroidectomy. Two patients had euthyroid Graves' disease (cases 3 and 9). Although they did not show signs of serum TSH receptor antibody activity, one had increased serum thyroglobulin levels and the other had a high titer of antimicrosomal antibody. One patient had hypothyroid Graves' disease (case 14). The clinical characteristics of the eye disease before steroid therapy are summarized in Table 1. All the patients had a normal chest $\mathrm{X}$ ray and upper gastrointestinal studies before the treatment. Six patients showed impaired glucose tolerance in $75 \mathrm{~g}$ oral glucose tolerance test.

Fifty-five normal subjects, 26 men and 29 women, aged 19-40 years (mean age 27 years) were studied for distribution of peripheral blood lymphocyte subpopulations. The serum from ten normal subjects, 5 men and 5 women, aged 24-40 years (mean age 32 years) was tested as controls for the presence of anti-eye muscle antibodies by ELISA. The apparently normal eyes of the 10 patients with unilateral eye disease, 5 men and 5 women aged 17-71 years (mean age 50 years), with orbital tumor or optic neuritis with no autoimmune thyroid disorders were studied as controls for MRI studies.

Table 1. Clinical characteristics of the patients with Graves' ophthalmopathy

\begin{tabular}{|c|c|c|c|c|c|c|c|c|c|c|c|c|c|c|c|}
\hline \multirow[t]{2}{*}{$\begin{array}{l}\text { Case } \\
\text { No. }\end{array}$} & \multirow[t]{2}{*}{$\begin{array}{c}\text { Age } \\
\text { (year) }\end{array}$} & \multirow[t]{2}{*}{ Sex } & \multirow[t]{2}{*}{$\begin{array}{l}\text { Present } \\
\text { treatment }\end{array}$} & \multirow{2}{*}{$\begin{array}{l}\text { Duration of } \\
\text { eye disease } \\
\text { (months) }\end{array}$} & \multicolumn{2}{|c|}{$\begin{array}{l}\text { Eye disease } \\
\text { A.T.A. classification }\end{array}$} & \multicolumn{2}{|c|}{$\begin{array}{l}\text { Proptosis } \\
(\mathrm{mm})\end{array}$} & \multicolumn{2}{|c|}{$\begin{array}{c}\mathrm{IOP} \\
(\mathrm{mmHg})\end{array}$} & \multirow[t]{2}{*}{$\begin{array}{c}\text { AMAB } \\
(n v<20)\end{array}$} & \multirow[t]{2}{*}{$\begin{array}{c}\text { ATAB } \\
(\mathrm{nv}<20)\end{array}$} & \multirow{2}{*}{$\begin{array}{c}\text { TBII } \\
(\%) \\
(\mathrm{nv}<10 \%)\end{array}$} & \multirow{2}{*}{$\begin{array}{c}\text { TSAB } \\
(\%) \\
(\mathrm{nv}<145 \%)\end{array}$} & \multirow[t]{2}{*}{$\begin{array}{c}\text { EMAB } \\
(n v<2.0)\end{array}$} \\
\hline & & & & & & & right & left & right & left & & & & & \\
\hline 1 & 25 & F & $\mathrm{T} 475 \mu \mathrm{g} / \mathrm{d}$ & 24 & V & (IIbIIIbIVbVa) & 23 & 23 & 19 & 19 & $<20$ & $<20$ & 8.7 & 777 & 2.5 \\
\hline 2 & 54 & M & MMI $5 \mathrm{mg} / \mathrm{d}$ & 24 & IV & IVb) & 20.5 & 18.5 & 18 & 18 & $<20$ & $<20$ & 24.5 & 345 & 2.8 \\
\hline 3 & 54 & $\mathrm{M}$ & - & 7 & IV & (IIbIIIaIVb) & 21 & 18 & 18 & 14 & $<20$ & $<20$ & 2.5 & 123 & 1.7 \\
\hline 4 & 21 & $\mathbf{M}$ & $\mathrm{T} 4100 \mu \mathrm{g} / \mathrm{d}$ & 44 & IV & (IIbIIIbIVb) & 23 & 19 & 25 & 25 & $<20$ & $<20$ & 25.9 & 107 & 5.7 \\
\hline 6 & 20 & $\mathrm{~F}$ & - & 15 & IV & (IIbIIIaIVa) & 20.5 & 21 & 13 & 14 & 400 & $<20$ & 62.3 & 5894 & NT \\
\hline 7 & 65 & $\mathrm{~F}$ & PTU $300 \mathrm{mg} / \mathrm{d}$ & 3 & IV & IVb) & 17 & 18 & 14 & 15 & 6400 & 6400 & 39.1 & 161 & 4.0 \\
\hline 8 & 75 & $\mathrm{M}$ & $\mathrm{T} 425 \mu \mathrm{g} / \mathrm{d}$ & 9 & IV & IVb) & 18 & 18 & 14 & 17 & 409600 & 400 & 75.8 & 2158 & 4.7 \\
\hline 9 & 51 & M & - & 5 & IV & IVa) & 13 & 10 & NT & NT & 25600 & $<20$ & 1.6 & 108 & NT \\
\hline 10 & 51 & $\mathrm{~F}$ & MMI $30 \mathrm{mg} / \mathrm{d}$ & 5 & IV & IVb) & 19 & 19 & 13 & 13 & $<20$ & $<20$ & 5.6 & 223 & NT \\
\hline 11 & 52 & $\mathrm{M}$ & $\mathrm{T} 450 \mu \mathrm{g} / \mathrm{d}$ & 6 & VI & (IIbIIIaIVbVaVIa) & 21 & 19 & 11 & 11 & 409600 & 409600 & 55.8 & 2880 & NT \\
\hline 12 & 31 & $\mathrm{~F}$ & - & 4 & IV & (IIb IVa) & 18 & 18 & 16 & 15 & 25600 & $<20$ & 9.7 & 215 & NT \\
\hline 13 & 67 & $\mathrm{~F}$ & MMI $5 \mathrm{mg} / \mathrm{d}$ & 4 & $\mathrm{~V}$ & (IIbIIIbIVbVa) & 23 & 22 & 16 & 13 & $<20$ & $<20$ & 52.1 & 1590 & 1.8 \\
\hline 15 & 54 & $\mathrm{M}$ & - & 5 & IV & IVb) & 18 & 17 & NT & NT & 1600 & $<20$ & 36.8 & NT & 2.9 \\
\hline
\end{tabular}

T4, levothyroxine; MMI, methimazole; A.T.A. classification, American Thyroid Association classification; IOP, intraocular pressure; $\mathrm{AMAB}$, anti-microsome antibodies; $\mathrm{ATAB}$, anti-thyroglobulin antibodies; TBII, thyrotropin binding inhibiting immunoglobulins; TSAB, thyroid stimulating antibody; EMAB, eye muscle antibody; NT, not tested; nv, normal value. 


\section{Ophthalmological evaluation}

All patients were assessed by the same ophthalmologist during the study. The degree of proptosis was measured with a Hertel exophthalmometer. Intraocular pressure was measured with an applanation tonometer in the primary position, which was recently reported to correlate to the severity and anti-eye muscle antibody activity assessed by antibody-dependent cell mediated cytotoxicity as well as IOP on upward gaze did [15]. The ocular movement was also assessed by means of the Hess chart. The eye sign changes were recorded according to an ophthalmopathy index [16] based on the American Thyroid Association classification for eye sign changes in GO. The ophthalmopathy index was calculated as the sum of the scores ( 0 to 3 ) for each class and ranged from 2 to 10 in this study.

\section{Magnetic resonance imaging (MRI)}

MRI of the orbits was obtained for the parasagittal, horizontal and coronal planes before and after steroid pulse therapy with a 0.5 -T superconducting MR unit (SMT50, Shimazu, Kyoto, Japan) with a surface coil (eye coil). Pulse sequences were as follows: spin echo 460/35 (repetition time msec/ echo time msec) for Tl-weighted images; spin echo 1800/100 for T2-weighted images; and inversion recovery 1500/100/40 (repetition time msec/ inversion time $\mathrm{msec} / \mathrm{echo}$ time $\mathrm{msec}$ ) for STIR (short inversion time inversion recovery) images. Section thickness was 7-8 $\mathrm{mm}$. The thickness of superior, medial and inferior rectus muscle was estimated at the site of their enlargement in the coronal section of the $\mathrm{T} 1$ weighted image. The thickness of the lateral rectus muscle was measured at the site of their enlargement in a horizontal section of the Tl weighted image. The enlargement of eye muscle was also expressed as the ratio of thickness of the eye muscle to the diameter of the optic nerve to avoid individual variation [17]. The signal intensity for the enlarged ocular muscle was also measured at the site of enlargement in the STIR image. Proptosis was also determined as the distance between the corneal eminence and the line connecting the two zygomatic bones in a horizontal section of the T1 weighted image. MRI was repeated at 1 week after the third or last cycles of the steroid pulse therapy in all cases. Muscle measurement was done on the same muscle and the same section as much as possible.

\section{Protocol of steroid pulse therapy}

Methylprednisolone was given for 3 days at a daily dosage of $1 \mathrm{~g}$ diluted in $200 \mathrm{ml}$ isotonic saline infused intravenously over $1 \mathrm{~h}$. The treatment was repeated 3-5 times for 3-5 weeks except for one patient (case 7) because of exacerbation of a gastric ulcer. The evaluation of the pulse therapy was completed within 2 weeks after the last cycle of the pulse therapy. After the evaluation 12 patients were given oral prednisolone $(20-30 \mathrm{mg} /$ day) for one month and then administration of the drug was tapered off over the next three months.

\section{Immunological evaluations}

The levels of serum eye muscle antibody (EMAB) to rat eye muscle membrane antigen $(100,000 \mathrm{~g}$ pellet $)$ were measured in 10 patients before and after steroid pulse therapy by ELISA as previously reported [18]. Five $\mu \mathrm{g} / \mathrm{m} l$ of membrane antigen was coated in 96 well-plates by incubation for $2 \mathrm{~h}$ at room temperature in carbonatebicarbonate buffer ( $\mathrm{pH}$ 9.6). After incubation with $1 \%$ bovine serum albumin in PBS for $1 \mathrm{~h}$, the plates were incubated with $100 \mu l$ of $1: 10$ diluted serum samples in $0.05 \%$ Tween 20 containing PBS for $1 \mathrm{~h}$ at $37^{\circ} \mathrm{C}$, followed by horseradish peroxidase labelled anti-human immunoglobulin $\mathrm{G}$ and substrate (O-Phenylendiamine). Tests were conducted at $492 \mathrm{~nm}$ in a micro-ELISA reader. EMAB were quantified according to an ELISA index, calculated as the the ratio between the optical density (OD) of each patient's serum sample and the mean OD of 10 normal control sera. Anti-thyroglobulin antibodies (ATAB) and anti-microsomal antibodies (AMAB) were measured with commercial kits (Serodia ATG and Serodia AMC, Fujirebio, Tokyo, Japan). Thyrotropin binding inhibiting immunoglobulins (TBII) were measured by radioreceptor assay (TRAK kit, Hoenning Berlin GmbH, Berlin, Germany). Thyroid stimulating antibodies (TSAB) were measured as the \% increase in cyclic AMP production by FRTL 5 cells [19]. 


\section{$T$ cell subsets}

Two-color analysis of peripheral blood lymphocytes before and after steroid pulse therapy was performed by flow cytometry as previously described [20]. Fluorescein isothiocyanate (FITC)- or phycoerythrin (PE)- labelled mouse monoclonal antibodies; CD4 (OKT4-FITC, Ortho, USA), CD8 (OKT8-FITC, Ortho and Leu3a-PE, Becton Dickinson, USA), CD11b (Mol-FITC, Coulter, USA), CD45RA (2H4-RD, Counter), HLA-DR (HLADR-PE, Becton Dickinson), CD57 (Leu7-FITC, Becton Dickinson) and CD16 (Leu 1 lc-PE, Becton Dickinson) were the reagents used.

\section{Statistical analyses}

Values obtained after treatment were compared with pretreatment values by Wilcoxon's and Student's paired $t$-test, and with normal controls by Student's unpaired $t$-test. Correlation coefficient among various parameters were calculated.

\section{Results}

Ophthalmological assessment

Loss of visual acuity was observed in two patients (cases 11 and 14). In case 11 , visual acuity was improved dramatically from 0.7 to 1.5 after the second cycle of pulse therapy, while in case 14, who had been blind for two months before therapy, there was no improvement in visual acuity. Fourteen patients complained of diplopia before treatment, which disappeared in 3 patients (cases 1, 2 and 9) and markedly improved in 6 other patients after steroid pulse therapy, while 2 patients remained unchanged. The improvement in eye muscle function was also observed by means of the Hess chart. Soft tissue involvements, including conjunctival injection and periorbital edema, were observed in all patients before therapy, and markedly decreased in 9 patients. Mean $( \pm$ SD) proptosis values for the 15 patients were significantly decreased after pulse therapy (from 19.4 \pm $3.0 \mathrm{~mm}$ to $18.4 \pm 2.1 \mathrm{~mm}$ in the right eye, Wilcoxon's test, and $P<0.05 ; 18.7 \pm 2.4 \mathrm{~mm}$ to $17.8 \pm 2.1 \mathrm{~mm}$ in the left eye, Wilcoxon's test, $P<0.05$, Fig. 1). Intraocular pressure was increased in 6 patients (cases $1-4,8,14$ ) and

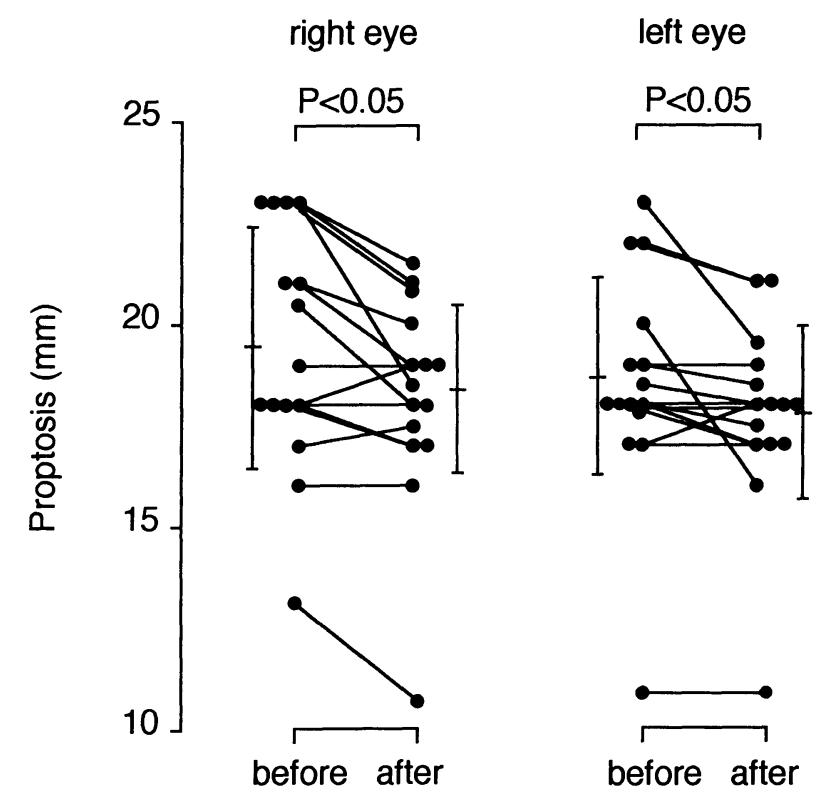

Fig. 1. Change in proptosis, measured by Hertel's exophthalmometer, after methylprednisolone pulse therapy. The horizontal lines and vertical bars indicate the means $( \pm S D)$.

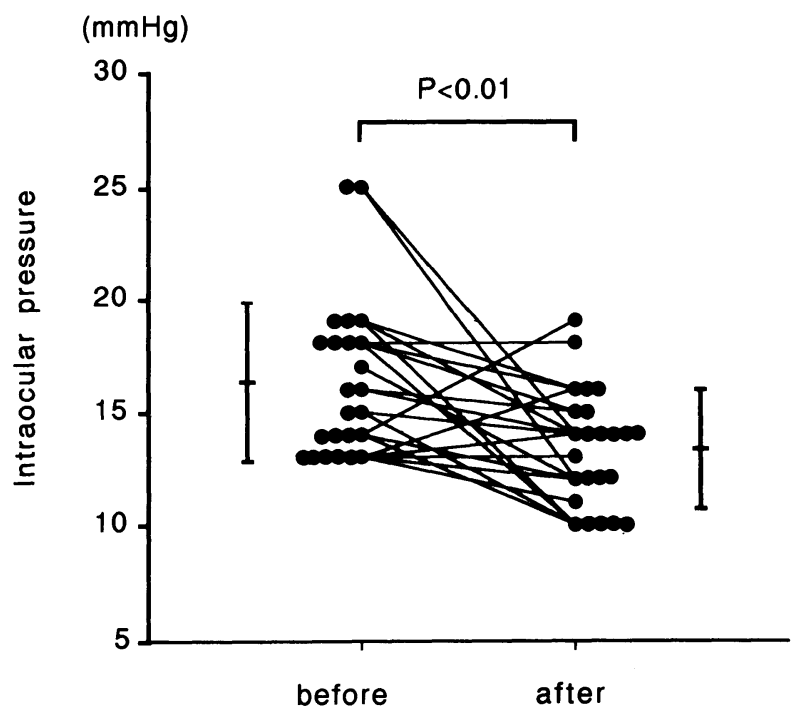

Fig. 2. Change in intraocular pressure in the primary position after pulse therapy. The horizontal lines and vertical bars indicate the means $( \pm \mathrm{SD})$ for 24 eyes.

decreased more than $3 \mathrm{mmHg}$ in these patients following methylprednisolone pulse therapy. Mean IOP measurements after pulse therapy $(13.4 \pm 2.6 \mathrm{mmHg})$ were significantly lower than those before therapy $(16.3 \pm 3.5 \mathrm{mmHg}$, Wilcoxon's test, $P<0.01$, Fig. 2). Corneal involvement was present in 4 patients at the beginning of therapy (three had stippling and one had cloudiness), and 
disappeared after pulse therapy. Mean $( \pm S D)$ ophthalmopathy index was changed from $4.8 \pm$ 2.4 to $2.5 \pm 1.6$ by pulse therapy $(P<0.01)$.

In the follow up periods of 6 months to one year, proptosis values (mean $\pm \mathrm{SD}$ of 30 eyes) tended to increase compared to that after pulse therapy, but they were still significantly lower than the pretreatment values $(18.1 \pm 2.0 \mathrm{~mm}$ at 6 months vs. $19.0 \pm 2.8 \mathrm{~mm}$ before therapy, $P<0.01$; $18.1 \pm 3.8 \mathrm{~mm}$ at one year, $P<0.01)$. The improvement in diplopia was also stable over a 6 to 24 month follow up period in all patients except one (case 7) in whom diplopia recurred three months after pulse therapy. The ophthalmopathy indexes 6 months and one year after pulse therapy were $2.4 \pm 1.5$ and $2.5 \pm 2.0$, respectively.

\section{MRI studies}

All patients had enlargement of one or more rectus muscles before therapy. Mean superior, medial, inferior and lateral rectus muscle thickness detected by MRI of 30 eyes before pulse therapy $(5.1 \pm 1.5 \mathrm{~mm}, 4.6 \pm 2.4 \mathrm{~mm}, 5.6 \pm 1.6 \mathrm{~mm}, 4.1 \pm$ $1.8 \mathrm{~mm}$, respectively) was significantly greater than in 10 normal control subjects $(2.0 \pm 1.1 \mathrm{~mm}$, $1.6 \pm 0.6 \mathrm{~mm}, 1.8 \pm 0.9 \mathrm{~mm}, 1.6 \pm 0.7 \mathrm{~mm}$, respectively, $P<0.01$, Fig. 3). After steroid pulse therapy, these enlarged rectus muscles had significantly decreased in size. Mean values for superior, medial, inferior and lateral rectus muscle thickness of 30 eyes after pulse therapy (4.2 \pm 1.5 $\mathrm{mm}, 3.7 \pm 1.5 \mathrm{~mm}, 4.5 \pm 1.3 \mathrm{~mm}, 3.7 \pm 1.8 \mathrm{~mm}$, respectively) were significantly smaller than the pretreatment values (Fig. 3). More than $1 \mathrm{~mm}$ of reduction of muscle thickness was observed in 9 patients for right superior rectus, 7 patients for medial rectus and 9 patients for inferior rectus muscle. More than an $80 \%$ reduction in thickness was observed in the right superior rectus muscle of 8 patients, the medial rectus muscle of 6 patients and the inferior rectus muscle of 9 patients (Table $3)$. When enlargement of the eye muscle was expressed as the ratio of the thickness of the eye muscle to the diameter of the optic nerve in a coronal or axial T1 weighted image, 12 patients (the right eye of 10 patients and the left eye of 8 patients) showed signs of improvement due to steroid pulse therapy. More than an $80 \%$ of reduction in these values following pulse therapy was observed in the right superior rectus muscle of 7 patients, the medial rectus muscle of 4 patients and the inferior rectus muscle of 9 patients (Table $3)$. The mean values for the superior and inferior rectus muscle were significantly decreased after pulse therapy [from $1.6 \pm 0.7$ to $1.3 \pm 0.3$ for the

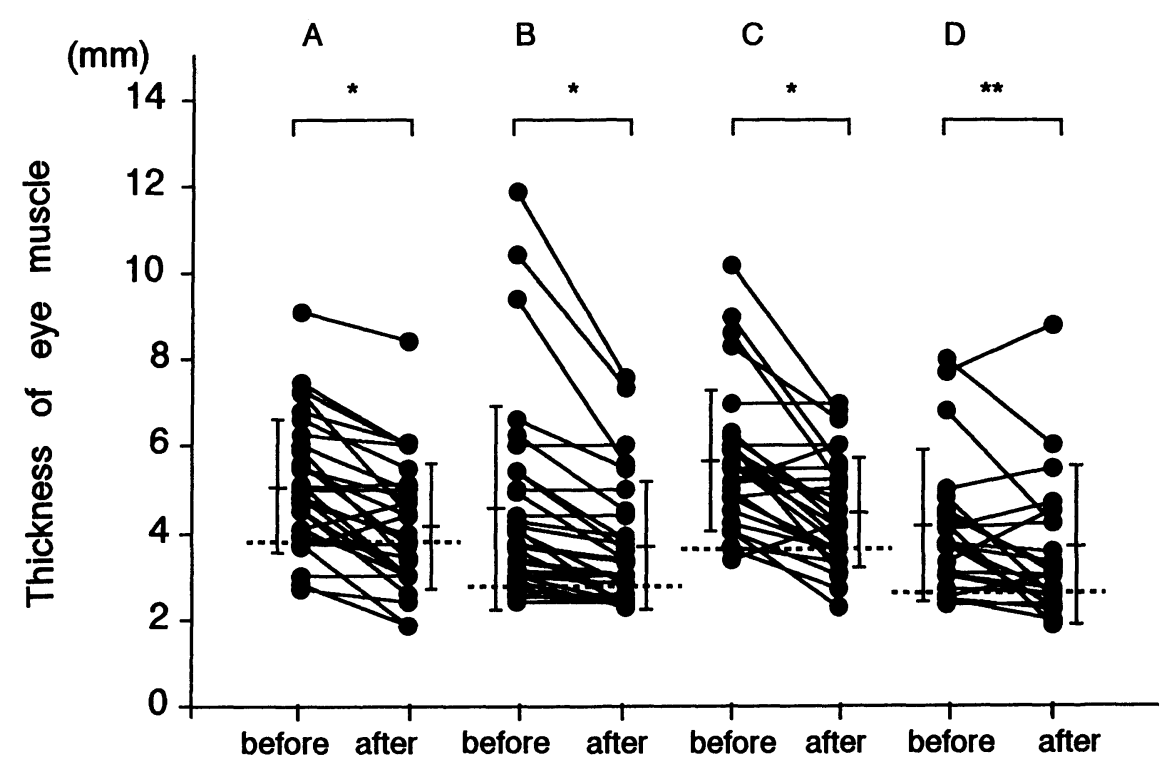

Fig. 3. Change in thickness of extraocular muscles after pulse therapy. The horizontal lines and vertical bars indicate the means $( \pm \mathrm{SD})$ for 30 eyes. The broken line indicates the upper limit of normal values (mean $+2 \mathrm{SD}$ ) for the control group $(\mathrm{N}=10)$. *, $P<0.01$; **, $P<0.05$. A, superior rectus muscle; $\mathrm{B}$, medial rectus muscle; $\mathrm{C}$, inferior rectus muscle; $\mathrm{D}$, lateral rectus muscle. 
Table 2. Changes in peripheral blood lymphocyte subpopulation (mean $\pm \mathrm{SD})$ in 7 patients with Graves' ophthalmopathy

\begin{tabular}{lccc}
\hline Subsets & $\begin{array}{c}\text { Before therapy } \\
(\%)\end{array}$ & $\begin{array}{c}\text { After therapy } \\
(\%)\end{array}$ & $\begin{array}{c}\text { Normal controls } \\
(\%)\end{array}$ \\
\hline $\mathrm{CD}^{+} \mathrm{CD}^{\circ} 5 \mathrm{RA}^{+}$ & $10.9 \pm 4.3$ & $14.4 \pm 6.2^{*}$ & $12.8 \pm 4.3$ \\
$\mathrm{CD}^{+} \mathrm{CD}^{+} 5 \mathrm{RA}^{-}$ & $27.1 \pm 10.1$ & $24.4 \pm 4.6$ & $22.7 \pm 6.7$ \\
$\mathrm{CD} 11^{-} \mathrm{CD} 8^{+}$ & $28.4 \pm 6.5^{* *}$ & $25.4 \pm 5.3$ & $21.5 \pm 5.7$ \\
$\mathrm{CD} 11^{+} \mathrm{CD} 8^{+}$ & $5.6 \pm 4.3$ & $7.2 \pm 5.8$ & $6.8 \pm 2.0$ \\
$\mathrm{CD} 11^{+} \mathrm{CD}^{++}$ & $1.8 \pm 0.9^{* * *}$ & $3.1 \pm 2.0$ & $3.1 \pm 1.4$ \\
$\mathrm{CD} 4^{+} \mathrm{HLA}^{-} \mathrm{DR}^{+}$ & $1.8 \pm 0.9$ & $2.2 \pm 1.1$ & $1.3 \pm 0.5$ \\
$\mathrm{CD} 8^{+} \mathrm{HLA}^{-} \mathrm{DR}^{+}$ & $2.4 \pm 1.7$ & $4.7 \pm 2.1$ & $3.0 \pm 1.0$ \\
$\mathrm{CD} 57^{+} \mathrm{CD} 16^{+}$ & $5.9 \pm 5.9$ & $6.4 \pm 6.3$ & $6.9 \pm 4.3$ \\
$\mathrm{CD} 57^{-} \mathrm{CD} 16^{+}$ & $4.3 \pm 4.1$ & $3.4 \pm 3.5$ & $7.4 \pm 3.1$ \\
$\mathrm{CD} 57^{+} \mathrm{CD} 16^{-}$ & $11.9 \pm 5.3$ & $9.0 \pm 1.8$ & $8.5 \pm 4.4$ \\
\hline
\end{tabular}

\footnotetext{
*, Statistically significant increase of $\mathrm{CD} 4{ }^{+} \mathrm{CD} 45 \mathrm{RA}^{+} \mathrm{T}$ cell subset compared to initial value $(P<0.05$, Wilcoxon's test). $* *$, Significant increase compared to normal subjects $(P<0.05$, Student's unpaired $t$-test $) . * * *$, Significant decrease compared to normal subjects $(P<0.05$, Student's unpaired $t$-test $)$.
}

Table 3. The changes in MRI findings following steroid pulse therapy

\begin{tabular}{|c|c|c|c|c|c|c|c|c|}
\hline \multirow[t]{2}{*}{ Case No. } & \multicolumn{2}{|c|}{ Proptosis $(\mathrm{mm})^{*}$} & \multicolumn{3}{|c|}{$\begin{array}{c}\text { Thickness of eye muscle }(\mathrm{mm})^{* *} \\
\text { right }\end{array}$} & \multicolumn{3}{|c|}{$\begin{array}{c}\text { Thickness of eye muscle } \\
\text { right }\end{array}$} \\
\hline & & & Superior & Medial & Inferior & Superior & Medial & Inferior \\
\hline 1 & $21.0(19.8)^{\mathrm{a}}$ & $22.0(19.8)$ & $6.6(5.5)$ & $6.6(5.5)$ & $5.5(4.8)$ & $1.5(1.1)$ & $1.5(1.1)$ & $1.3(1.0)$ \\
\hline 2 & $18.7(16.9)$ & $18.7(17.0)$ & $5.0(5.0)$ & $5.0(5.0)$ & $6.0(6.0)$ & $1.4(1.2)$ & $1.4(1.2)$ & $1.7(1.5)$ \\
\hline 3 & $23.0(20.5)$ & $21.3(19.8)$ & $3.0(3.0)$ & $4.3(3.9)$ & $8.6(5.2)$ & $0.9(0.9)$ & $1.3(1.2)$ & $2.5(1.6)$ \\
\hline 4 & $22.0(22.0)$ & $19.0(19.0)$ & $4.1(4.7)$ & $2.9(2.3)$ & $5.9(4.5)$ & $1.0(1.6)$ & $0.7(0.8)$ & $1.5(1.5)$ \\
\hline 5 & $16.0(16.5)$ & $16.0(16.5)$ & $5.5(4.4)$ & $2.5(2.6)$ & $3.7(3.3)$ & $1.7(1.6)$ & $0.8(0.9)$ & $1.1(1.2)$ \\
\hline 6 & $20.5(19.0)$ & $21.4(19.0)$ & $4.5(3.0)$ & $3.6(2.4)$ & $4.5(3.6)$ & $1.5(1.3)$ & $1.2(1.1)$ & $1.5(1.6)$ \\
\hline 7 & $18.5(16.5)$ & $18.5(17.4)$ & $5.1(5.1)$ & $4.1(2.9)$ & $4.1(2.3)$ & $1.0(1.3)$ & $0.8(0.7)$ & $1.8(0.6)$ \\
\hline 8 & $18.5(18.5)$ & $18.5(18.5)$ & $5.6(3.8)$ & $4.1(3.8)$ & $9.0(5.6)$ & $1.3(0.9)$ & $0.9(0.9)$ & $2.0(1.4)$ \\
\hline 9 & $13.5(13.5)$ & $13.5(13.5)$ & $5.1(3.0)$ & $2.7(2.4)$ & $4.1(3.0)$ & $1.5(0.8)$ & $0.8(0.7)$ & $1.2(0.8)$ \\
\hline 10 & $19.0(18.6)$ & $19.0(18.6)$ & $4.5(2.6)$ & $5.4(3.6)$ & $6.0(3.1)$ & $1.3(1.1)$ & $1.5(1.5)$ & $1.7(1.3)$ \\
\hline 11 & $19.3(16.6)$ & $16.7(16.6)$ & $9.1 \quad(8.4)$ & $10.4(7.4)$ & $5.2(5.3)$ & $3.5(1.9)$ & $4.0(1.7)$ & $2.0(1.2)$ \\
\hline 12 & $17.8(17.9)$ & $17.8(17.4)$ & $3.8(2.2)$ & $1.7(1.8)$ & $3.8(2.2)$ & $1.3(1.3)$ & $0.6(1.1)$ & $1.3(1.3)$ \\
\hline 13 & $23.7(21.4)$ & $23.7(21.4)$ & $6.3(6.0)$ & $6.3(4.5)$ & $8.3(6.6)$ & $3.0(1.6)$ & $3.0(1.2)$ & $4.0(1.8)$ \\
\hline 14 & $17.9(16.3)$ & $23.0(16.3)$ & $5.9(3.4)$ & $4.9(3.4)$ & $3.4(4.2)$ & $1.7(1.1)$ & $1.4(1.1)$ & $1.0(1.4)$ \\
\hline 15 & $16.6(16.7)$ & $16.6(16.7)$ & $7.5(6.0)$ & $3.0(3.0)$ & $4.8(3.6)$ & $2.0(1.6)$ & $0.8(0.8)$ & $1.3(1.0)$ \\
\hline
\end{tabular}

*, Proptosis determined as distance between corneal eminence and line connecting both zygomatic bones in horizontal section of $\mathrm{T} 1$ weighted image. ${ }^{* *}$, Thickness of eye muscle measured at the site of greatest enlargement of the muscle (mm) in coronal section of T1 weighted image. ${ }^{* * *}$, Thickness of eye muscle expressed as the ratio of thickness of enlarged eye muscle to diameter of the optic nerve in coronal section of T1 weighted image. Superior, superior rectus muscle; Medial, medial rectus muscle; Inferior, inferior rectus muscle. a, Values, evaluated before and after pulse therapy. Values after pulse therapy are indicated in parentheses.

right superior rectus muscle $(P<0.05)$ and from $1.7 \pm 0.8$ to $1.3 \pm 0.3$ for the right inferior rectus muscle $(P<0.05)$ ], but those for the medial rectus muscle did not decrease significantly [from 1.4 0.9 to $1.1 \pm 0.3$ for the right eye $(P=0.12)]$. Proptosis measured by MRI was also markedly decreased in 8 patients by the pulse therapy (Table $3)$. Mean proptosis values measured by MRI in 15 patients were significantly decreased from 19.1 2.7 to $18.0 \pm 2.3 \mathrm{~mm}$ for the right eye $(P<0.01)$ and from $19.0 \pm 2.9$ to $17.8 \pm 1.9 \mathrm{~mm}$ for the left eye $(P<0.05)$. There was a significant correlation between proptosis and thickness measured by MRI before $(\mathrm{r}=0.45, \quad P<0.01)$ and after therapy $(\mathrm{r}<0.54, P<0.01)$. Although there were significant correlations between the thickness of the eye muscle before therapy and its improvement after pulse therapy $(\mathrm{r}=0.93, P<0.01)$ and proptosis before therapy and its improvement after therapy $(\mathrm{r}=0.57, P<0.05)$, there was no significant correla- 
tion between the improvement in eye muscle thickness and that of proptosis $(\mathrm{r}=0.22, P<0.14)$. The duration of eye disease did not correlate to the improvement in exophthalmos or enlargement of the eye muscle. The signal intensity of the enlarged muscles before therapy was iso-intensity in the T1 weighted image, iso-or high intensity in the T2 weighted image and high intensity in the STIR image, as compared to that for the temporal muscles, indicating edematous changes in these muscles [21]. After the pulse therapy the intensity of the enlarged eye muscle in the STIR image tended to decrease.

\section{Immunological assessment}

TSH receptor antibodies, assessed as TBII were detected in the sera from 9 patients, and their levels decreased after pulse therapy (the mean TBII percentage changed from $29.8 \pm 23.5 \%$ to $21.7 \pm 22.2 \%$ (Fig. $4 \mathrm{~A}$ ). TSAB was recognized in 11 out of 14 patients and the antibody levels were decreased in 10 patients. Eye muscle antibodies, assessed as the ELISA index, were found in the sera from 8 out of 10 patients tested before treatment. The ELISA index significantly decreased after pulse therapy $(P<0.01$, Wilcoxon's test, Fig. 4B). AMAB were detected in the sera from 8 patients and $\mathrm{ATAB}$ were in 4 patients before pulse therapy. The levels of these anti- bodies decreased after pulse therapy, but before therapy none of these antibodies correlated to the improvement in proptosis or thickness of the eye muscle.

\section{Peripheral blood lymphocyte subsets}

Peripheral blood lymphocyte subsets were analyzed in 7 patients before and after pulse therapy. The results are summarized in Table 2. Although normal controls were not completely age-matched, there was a significant increase in $\mathrm{CD}_{1} 1^{-} \mathrm{CD}^{+} \mathrm{T}$ cells (cytotoxic $\mathrm{T}$ cells) and a decrease in $\mathrm{CD}_{1} 1^{+} \mathrm{CD}^{++} \mathrm{T}$ cells (suppressor $\mathrm{T}$ cells) in the peripheral blood of patients before therapy. These abnormalities were normalized after pulse therapy. The $\mathrm{CD} 4{ }^{+} \mathrm{CD} 45 \mathrm{RA}^{+} \mathrm{T}$ cell subset, which is considered to represent suppressor-inducer $T$ cells, was found to be smaller than that of normal subjects. After pulse therapy the $\mathrm{CD}^{+}{ }^{+} \mathrm{CD} 45 \mathrm{RA}^{+} \mathrm{T}$ cell subset $(14.4 \pm 6.2 \%)$ was significantly increased compared to the initial value $(10.8 \pm 4.3 \%, P<0.05)$. NK cell subsets did not significantly change during pulse therapy.

\section{Adverse reactions}

Although prophylactic anti-ulcer drugs were given, gastric ulcer was observed in two patients, both of whom had a history of gastric ulcer (cases 7
A

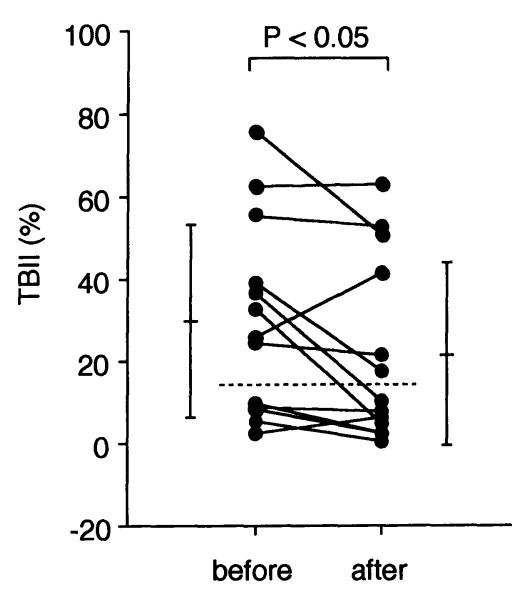

B

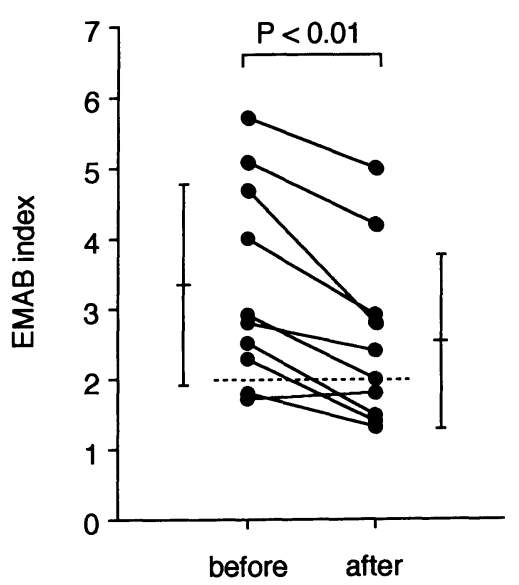

Fig. 4. Change in level of (A) thyrotropin binding inhibiting immunoglobulins (TBII) in 15 patients with Graves' ophthalmopathy and (B) antibody to rat eye muscle antigen in 10 patients with Graves' ophthalmopathy. The horizontal lines and vertical bars indicate the means $( \pm S D)$. The broken line indicates the upper limit of the normal values $(<15 \%$ for TBII, 2.06 for antibody to eye muscle, $\mathrm{N}=10$ ). 
and 9). They were effectively treated with an anti- $\mathrm{H}_{2}$ blocker. Sinusitis was observed in one patient and was effectively treated with antibiotics. Two patients (cases 3 and 12) had a transient (1 to 3 months) increase in serum levels of GOT $(81 \mathrm{KU}$, $52 \mathrm{KU}$, respectively) and GPT $(258 \mathrm{KU}, 86 \mathrm{KU}$, respectively) one month after the last cycle of pulse therapy. One patient (case 8) needed insulin injections during pulse therapy because of increased plasma glucose. No other adverse reactions were observed during treatment.

\section{Discussion}

It is now accepted that GO has an autoimmune pathogenesis [1]. In the treatment of GO, immunosuppressive drugs alone or in association with plasmaphresis, or radiotherapy has been used [4-8]. The results of these treatments have not been assessed as completely satisfactory. Recently, Bartalena et al. [9] designed a study on the use of prednisolone to prevent the development of GO following radioactive iodine treatment for hyperthyroidism. These authors were able to show a protective effect of systemic corticosteroid therapy on the exacerbation of GO. In addition KendallTaylor et al. [11] reported distinct improvement in eye signs of GO with treatment based on intravenous methylprednisolone in eight of $11 \mathrm{pa}$ tients with active GO, which was also confirmed very recently by Dandona $e t$ al. [12] who showed a reduction in the exophthalmos in their GO patients. In the present study we have obtained comparable results with a similar methylprednisolone pulse therapy in the treatment of active GO. We employed MRI to objectively assess the effect of the pulse therapy for proptosis and enlargement of eye muscles in addition to the conventional ophthalmological measurements. In 12 patients enlargement of the eye muscles responded well to pulse therapy and diplopia, and periorbital edema were also improved by pulse therapy in most of the patients. In contrast, exophthalmos, assessed by either Hertel's exophthalmometer or MRI, and increased IOP improved in only half of the patients. Although there was a significant correlation between eye muscle thickness and proptosis, in four patients eye muscle thickness decreased after pulse therapy, but their proptosis values did not improve. These results suggest that the eye muscle changes may be irreversible at the time of the study because of some adhesion. In the present study we also expressed the eye muscle thickness as a ratio of this value to the diameter of the optic nerve as well as the thickness $(\mathrm{mm})$ at the site of the greatest enlargement. More than an $80 \%$ reduction in these values and significant reduction in the mean values were more frequently observed when the enlargement of eye muscle was expressed as the actual thickness than done as the ratio to the optic nerve. The number of patients tested was too small to conclude which estimation was better for muscle enlargement.

TSH receptor antibody activities decreased after the pulse therapy, but no correlation between these antibody activities and proptosis or eye muscle thickness was found. The failure to detect TSAB in euthyroid Graves' patients may be due to the low sensitivity of the assay employed in this study.

Serum eye muscle antibodies, which have been demonstrated in the serum of patients with GO, by ELISA [18, 22-24], immunofluorescence [25], antibody-dependent cell mediated cytotoxicity [2, 3] and Western blotting [26], were also measured in the serum of the patients in this study. The precise role of eye muscle antibodies and antibodies to thyroid and eye muscle/shared antigens, which were recently described in the serum of patients with GO [3, 26], in the development of GO, is not yet fully understood. In our study, serum antibodies to rat eye muscle membrane were detected in 8 out of 10 patients tested by ELISA before the initiation of treatment, and their levels declined after treatment. Since steroids have an immunosuppressive effect, exerted on various immuno-competent cell as well as an antiinflammatory effect [27], the decrease in eye muscle antibody levels might be due to the drug effects on both $\mathrm{B}$ and $\mathrm{T}$ cell populations, possibly resulting in decreased immunoglobulin production. Indeed, we were also able to show increases in the suppressor-inducer $\mathrm{T}$ cell subset, defined as $\mathrm{CD}^{+}{ }^{+} \mathrm{CD} 45 \mathrm{RA}^{+} \mathrm{T}$ cells, and the suppressor $\mathrm{T}$ cell subset $\left(\mathrm{CD}_{1} 1^{+} \mathrm{CD}^{++}\right)$in the peripheral blood after pulse therapy. Whether these changes are due to the steroid treatment is, of course, unproven although likely. Prospective studies are indicated to further evaluate which of the immune reactions are relevant to the development of GO and what effect steroid treatment may exert on 
these.

Although the number of GO patients studied was small and the present study lacked a control treatment group, we believe that we have objectively shown both clinical and immunological improvement in the ophthalmopathy, with MRI, ELISA, flow cytometry and with steroid pulse therapy in particular, when the disease was of recent onset and active. The lack of a potent tool to evaluate the activity of ophthalmopathy may result in an unsatisfactory clinical response to steroid pulse therapy. However, it is important to diagnose and treat during the early stages of GO. Trials are now in progress in our laboratory to solve these problems with MRI and western blotting for eye muscle antibodies.

\section{References}

1. Wall JR, Salvi M, Bernard NF, Boucher A, Haegert D (1991) Thyroid-associated ophthalmopathy-A model for the association of organ-specific autoimmune disorders. Immunol Today 12: 150-153.

2. Hiromatsu Y, Fukazawa H, How J, Wall JR (1987) Antibody-dependent cell-mediated cytotoxicity against human eye muscle cells and orbital fibroblasts in Graves' ophthalmopathy-Roles of class II MHC antigen expression and $\gamma$-interferon action on effector and target cells. Clin Exp Immunol 70: 597-603.

3. Hiromatsu Y, Fukazawa H, Guinard F, Salvi M, How J, Wall JR (1988) A thyroid cytotoxic antibody that cross-reacts with an eye muscle cell surface antigen may be the cause of thyroid associated ophthalmopathy. J Clin Endocrinol Metab 67: 565570 .

4. Werner SC (1966) Prednisone in emergency treatment of malignant exophthalmos. Lancet II: 10041007.

5. Wall JR, Strakosch CR, Fang SH, Braverman LE (1979) Thyroid binding antibodies and other immunological abnormalities in patients with Graves' ophthalmopathy: Effect of treatment with cyclophosphamide. Clin Endocrinol 10: 79-91.

6. Weetman AP, McGregor AM, Ludgate M, Beck L, Mills PV, Lazarus JH (1983) Cycrosporin improves Graves' ophthalmopathy. Lancet II:486-489.

7. Prummel MF, Mourits MPh, Berghout A, Krenning EP, Van der Gaag R, Koornneef L, Wiersinga WM (1989) Prednisone and cyclosporine in the treatment of severe Graves' ophthalmopathy. $N$ Engl J Med 321: 1353-1359.

8. Dandona P, Marshall N, Bidey S, Nathan AW, Havard CWH (1979) Exophthalmos and pretibial myxoedema not responding to plasmapheresis. $\mathrm{Br}$ Med J 2: 667-668.

9. Bartalena L, Marcocci C, Bogazzi F, Panicucci M, Lepri A, Pinchera A (1989) Use of corticosteroids to prevent progression of Graves' ophthalmopathy after radioiodine therapy for hyperthyroidism. $N$ Engl J Med 321: 1349-1352.

10. Nagayama $\mathrm{Y}$, Izumi M, Kiriyama T, Yokoyama N, Morita S, Kakezono F, Ohtakara S, Morimoto I,
Okamoto S, Nagataki S (1987) Treatment of Graves' ophthalmopathy with high-dose intravenous methylprednisolone pulse therapy. Acta Endocrinol 116: 513-518.

11. Kendall-Taylor P, Crombie AL, Stephenson AM, Hardwick M, Hall K (1988) Intravenous methylprednisolone in the treatment of Graves' ophthalmopathy. $\mathrm{Br}$ Med J 297: 1574-1578.

12. Dandona P, Havard CWH, Mier A (1989) Methylprednisolone and Graves' ophthalmopathy. $\mathrm{Br} \mathrm{Med}$ J 298: 830.

13. Cathcart ES, Idelson BA, Scheinberg MA, Couser WG (1976) Beneficial effects of methylprednisolone "pulse" therapy in diffuse proliferative lupus nephritis. Lancet I: 163-166.

14. Werner SC (1977) Modification of the classification of the eye change of Graves' disease: Recommendation of the Ad Hoc Committee of the American Thyroid Association. J Clin Endocrinol Metab 44: 203-204.

15. Hiromatsu Y, Cadarso L, Salvi M, Wall JR (1990) Significance of cytotoxic eye muscle antibodies in patients with thyroid-associated ophthalmopathy. Autoimmunity 5: 205-213.

16. Donaldson SS, Bagshaw MA, Kriss JP (1973) Supervoltage orbital radiotherapy for Graves' ophthalmopathy. J Clin Endocrinol Metab 37: 276285.

17. Izumi M, Nagataki S (1991) A new method for the evaluation of the effects of treatment on Graves' ophthalmopathy. Folia Endocrinol Japon 67: 112120 (In Japanese).

18. Kaise K, Kaise K, Yoshida K, Itagaki Y, Arai T, Kiso Y, Yamamoto M, Sakurada T, Saito S, Yoshinaga K (1988) Antibodies to rat retro-orbital antigens in patients with Graves' ophthalmopathy. 63rd Meetings of American Thyroid Association, Montreal, Canada (Abstract 10).

19. Kasagi K, Konishi J, Iida Y, Tokuda Y, Arai K, Endo K, Torizuka K (1987) A sensitive and practical assay for thyroid-stimulating antibodies using FRTL-5 thyroid cells. Acta Endocrinol 115: 30-36.

20. Hiromatsu Y, Sato M, Kuroki T, Nonaka K (1989) 
Two-color analysis of peripheral blood $\mathrm{T}$ and natural killer (NK) cells in patients with Graves' disease. In: Lee M, Koh C-S, Eastman CJ, Nagataki $S$ (eds) Progress in Thyroidology 1989. Korea Medical Publishing Co., Seoul, Korea: 115-118.

21. Hosten N, Sander B, Cordes M, Schubert CJ, Schorner W, Felix R (1989) Graves' ophthalmopathy: MR imaging of the orbits. Radiology 172: 759-762.

22. Kodama K, Sikorska H, Bandy-Dafoe P, Bayly R, Wall JR (1982) Demonstration of a circulating autoantibody against a soluble eye-muscle antigen in Graves' ophthalmopathy. Lancet II: 1353-1356.

23. Kendall-Taylor P, Atkinson S, Holcombe M (1984) A specific IgG in Grave's ophthalmopathy and its relation to retro-orbital and thyroid autoimmunity. Br Med J 288:1183-1186.
24. Faryna M, Nauman T, Gardas A (1985) Measurement of autoantibodies against human eye muscle plasma membranes in Graves' ophthalmopathy. $\mathrm{Br}$ Med J 290: 191-192.

25. Mengistu M, Laryea E, Miller A, Wall JR (1986) Clinical significance of a new autoantibody against a human eye muscle soluble antigen detected by immunofluorescence. Clin Exp Immunol 65: 19-27.

26. Salvi M, Miller A, Wall JR (1988) Human orbital tissue and thyroid membranes express a $64 \mathrm{kDa}$ protein which is recognized by autoantibodies in the serum of patients with thyroid-associated ophthalmopathy. FEBS Letters 232: 135-139.

27. Webel ML, Ritts RE, Taswell HF Jr, Donadio JV Jr, Woods JE (1974) Cellular immunity after intravenous administration of methylprednisolone. $J$ Lab Clin Med 83: 383-392. 